\title{
A produtividade acadêmica como imperativo moral: do sofrimento ao tédio*
}

\author{
Pedro Fernando da Silva ${ }^{a}$ \\ Gustavo Martineli Massolab \\ Cintia Copit Freller ${ }^{a * *}$ \\ aUniversidade de São Paulo, Instituto de Psicologia, Departamento de Psicologia da Aprendizagem, \\ do Desenvolvimento e da Personalidade. São Paulo, SP, Brasil \\ 'Universidade de São Paulo, Instituto de Psicologia, Departamento de Psicologia Social e do Trabalho. São Paulo, SP, Brasil
}

Quem se propõe a fazer a crítica, vê-se frequentemente diante da exigência utilitarista de ter de propor algo no lugar do que é criticado, com isso, é compelido a ignorar que a crítica, por si mesma, já é parte da ação transformadora, e que o que deve ser modificado não é somente o seu alvo específico, mas a totalidade social que o conforma. Como efeito, essa exigência se converte em acusação ao momento de liberdade do pensamento; converte-se em acusação à crítica.

Tal acusação paralisa o pensamento, tolhido pela ameaça de ser inútil e impotente, mas cuja percepção de inutilidade - não se acorrentando a nenhum objetivo imediato - e de impotência - cujo reconhecimento é fundamental para superar esse limite - são fundamentais. Torna-se resignado. A pergunta: "o que fazer?" pode interromper a crítica que permitiria vislumbrar a ação adequada.

Certamente, a "crítica pela crítica", a "crítica sem substância", "a rebeldia sem causa" devem ser postas em questão, mas, quando se refuta a crítica que se refere aos limites do que é refletido, indicando pela negação o que está sendo sacrificado e o que poderia vir a ser, a própria crítica é sacrificada.

Como tudo mais que há na sociedade capitalista tardia, caracterizada pelo antagonismo entre as classes sociais e pela predominância dos processos calcados no princípio da dominação que reduz os trabalhadores a apêndices da maquinaria, por meio da qual são "forzados en sus más íntimas emociones a adherirse al mecanismo social como portadores de un rol y a modelarse sin reservas según este mecanismo" (Adorno, 1968/2004, p. 336), a universidade brasileira e os centros de pesquisa parecem também não estar isentos do modus operandi da produção industrial. Estão repletos de contradições de difícil análise, de modo que a organização do trabalho intelectual que tem prosperado em seu núcleo acaba por impor a pesquisadores, docentes e estudantes uma forma específica de relação com o conhecimento, e com sua respectiva divulgação, que em muito se assemelha à lógica da produção industrial, reproduzindo, na esfera do pensamento supostamente autônomo, a

\footnotetext{
* As críticas manifestadas neste editorial não expressam, necessariamente, o entendimento de toda a equipe editorial da revista Psicologia USP, mas, sim, dos editores que $\mathrm{o}$ assinam.

** Endereço para correspondência: revpsico@usp.br
}

mesma racionalidade tecnológica que primeiramente foi desenvolvida com o intuito de incrementar a produção material e a acumulação de capital (Marcuse, 1964/2015).

O notório esforço representado pelo novo Marco Legal da Ciência, Tecnologia e Inovação - Lei $\mathrm{n}^{\mathrm{o}}$ 13.243/2016 - para aproximar a universidade brasileira, bem como a sua seleta produção, da sociedade que a produz em acordo com o intuito principal de atender aos interesses econômicos hegemônicos - embora esteja repleta de outras demandas efetivas comumente negligenciadas - carece de reflexão sobre suas metas, pois parece se esquecer de que a sociedade, como uma totalidade complexa que se realiza em cada particular que a compõe, não se resume às instituições sociais produtivas. Na órbita dessa contradição destaca-se o abismo existente entre as instituições de ensino superior públicas, historicamente consolidadas e reconhecidas como produtoras de saber, e o crescente conjunto de instituições de ensino superior particulares, sobre as quais paira, de modo não inteiramente injustificado, certa desconfiança quanto às intenções mercadológicas que estariam subjacentes a seu empenho para se firmarem como referências no âmbito da formação e, mais recentemente, da produção de pesquisa stricto sensu. Salvaguardadas as excelentes qualidades de instituições públicas e privadas que priorizam a formação e a produção de conhecimentos de grande relevância social, a crítica à subordinação de ambos os tipos de instituições de ensino e de pesquisa à racionalidade própria à produção industrial deve se voltar também para o fato de que o abismo que as separa radicalmente tende a ser apenas ideologia. Tanto a idealização quanto a desqualificação apressadas de cada um dos dois modelos de universidade, de fato, contrastantes por muitos motivos objetivos, exaustivamente demonstrados por pesquisas voltadas à análise de suas gestões, da formação oferecida e das condições de trabalho nelas asseguradas a docentes e a pesquisadores, minimiza a funesta identidade que há entre ambas no que se refere à mediação exercida por uma politica nacional de ciência e tecnologia, agora marcadamente associada à temerária ideia de inovação.

Não raro, frequentemente nos deparamos com as intensas queixas de colegas devotados ao magistério superior em instituições privadas, alheias ao desenvolvimento de pesquisas, nas quais são 
massacrados pelo excesso de trabalho e pela remuneração incompatível quer com seu nível de formação, quer com a manutenção de necessidades básicas para o exercício de suas funções como trabalhadores intelectuais. Antes mesmo de serem sistematizadas como dado primário de pesquisa, diversamente das críticas às condições de trabalho docente proferidas por órgãos sindicais munidos de dados e da análise histórica dos acontecimentos que resultaram no atual nível de degradação da formação, essas queixas representam uma manifestação do modo como cada trabalhador intelectual experimenta sua relação com o conhecimento e com as instituições que se impõem como mediadoras da sua produção. Podem até ser dotadas de excelente fundamentação em dados empíricos já sistematizados ou elevados à reflexão teórica, mas, ainda assim, são também expressões emocionais do impacto que as condições de trabalho e de recepção de seus esforços provocam em suas vidas pessoais, no núcleo de suas existências particulares.

As exigências até pouco tempo percebidas como específicas das condições de trabalho próprias de cada tipo de instituição têm se revelado muito mais fluídas e generalizáveis do que previa a bem-intencionada, porém rígida, sistematização das diferenças e especificidades das contradições que contaminam a educação superior e a pesquisa brasileiras. A exigência de que os docentes assumam um grande volume de horas-aula, inclusive responsabilizando-se por disciplinas sobre cujos conteúdos não são especialistas e em relação aos quais, cada vez menos, têm possibilidades de se dedicarem suficientemente, de modo a se apropriarem na proporção necessária para que possam ministrar aulas consistentes; ou, de outro lado, a exigência de que produzam um volume elevado de papers, relatórios, pareceres, conferências etc., de modo a assegurarem sua sobrevivência acadêmica como pesquisadores vinculados aos programas de Pósgraduação, são situações menos descontínuas do que sugere o discurso que comumente justifica a manutenção dessas condições pouco propícias ao trabalho intelectual. A vida acadêmica contemporânea, dotada ou privada da aura de nobreza, que muitas vezes assegurou a muitos sua distinção intelectual, tem sido absorvida por tarefas e mais tarefas que impossibilitam aquilo mesmo que deveria qualificá-la: a reflexão detida e aprofundada. Quer os docentes horistas vinculados às universidades particulares de caráter mercadológico, que se veem tragados pela reprodução serial de conteúdos padronizados supostamente ligados a uma formação tecnicamente eficiente para o trabalho, quer os docentes pesquisadores vinculados às instituições de ensino superior e de pesquisa públicas, submetidas aos sistemas de avaliação da produtividade intelectual e de seu suposto impacto na sociedade (Oliveira, 2015) - cuja manutenção requer que se convertam em eficazes empreendedores capazes de captar recursos financeiros de agências públicas de fomento nacionais e internacionais, bem como, cada vez mais, de fundações e de empresas públicas e particulares com interesses bem delimitados, porém não raro alheios ao campo científico -, estão igualmente susceptíveis ao desgaste contínuo das condições que, em condições adequadas, lhes assegurariam a produção intelectual pela qual são rigidamente avaliados e, a depender de seu desempenho, severamente punidos (Schmidt, 2011): o volume de horas-aula, o excesso de trabalhos administrativos e a ausência de recursos que possibilitem a dedicação à pesquisa funcionam como formas de punição para os que não se ajustam ao modelo de produção intelectual requerido, o qual tem se tornado a principal mediação para o ingresso e a ascensão na carreira acadêmica. Ambas as condições são faces de um mesmo processo que, muitas vezes, lamentavelmente, subordina a formação e o trabalho acadêmico a interesses de reprodução do capital.

É nesse contexto de intensa pressão, cujos efeitos ainda imprevistos já incluem a perda do emprego realidade corriqueira para docentes com vínculos de trabalho precários com instituições públicas e privadas, porém já configurada também para docentes e pesquisadores estáveis de universidades públicas tradicionais, sobretudo em razão da adoção das novas formas de avaliação de desempenho que preveem punições por baixa produtividade -, que as queixas de nossos colegas são produzidas. Seu potencial de crítica não decorre apenas da veracidade dos fatos que espelham as situações que as produzem, mas do sofrimento que explicita. E é sobre ele que se discorre nesta brevíssima reflexão sobre a transformação da produtividade acadêmica em imperativo moral.

Apesar de ambos os produtos do trabalho acadêmico aqui destacados serem essencialmente produções intelectuais, a desvalorização dessas atividades tem uma direção específica, que resulta na grotesca divisão do trabalho acadêmico, sob a justificativa de que atenderia às diferenças de aptidão: lecionar se tornou uma atividade pouco valorizada pelas avaliações em voga e, não obstante a sua necessidade premente, paradoxalmente, converte-se em "castigo" para os pesquisadores considerados improdutivos.

A partir dessa consideração crítica inicial, tomamos como objeto de reflexão, neste texto, o fato de que a produção intelectual se tornou mais que uma insígnia da excelência, converteu-se em um imperativo moral que, por não ser factível na proporção e do modo exigidos, é expressão de um tipo de sofrimento laboral pouco reconhecido.

A despeito das inúmeras controvérsias sobre as implicações éticas dessa política de administração acadêmica que toma alguns indicadores - número de publicações em periódicos bem avaliados e de citações por pares - como decisivos para a definição da almejada excelência, é a capacidade de produzir e publicar artigos científicos que tem se firmado como determinante da conduta dos pesquisadores; mesmo que em muitos casos isso ocorra à custa da adoção de meios espúrios, como as 
diversas modalidades de fraudes, propagadas de forma epidêmica mundo afora e comumente enfrentadas de modo moralizador, embora flagrantemente ineficaz, como indica Oliveira (2015): "A ineficácia é o defeito mais decisivo do tratamento moralizador. Levando em conta que vem sendo aplicado há décadas, particularmente nos Estados Unidos, as pesquisas mais recentes que comprovam a epidemia constituem também evidências do fracasso do tratamento moralizador" (p. 886).

As inúmeras falhas do processo avaliativo são pouco consideradas na discussão: diversas formas de plágio e autoplágio; a apropriação indevida da produção alheia, inclusive por meio da automatização da publicação conjunta com orientandos de cursos de pós-graduação e colaboradores; a fragmentação e a repetição serial de resultados de pesquisa em produções que não se diferenciam substancialmente, mas, antes, se repetem sem nada acrescentar; a mediação financeira do processo de submissão e publicação de manuscritos por publishers comerciais que têm fomentado a crescente profissionalização da publicação acadêmica etc. Em consequência, tanto os pesquisadores muito produtivos quanto os considerados improdutivos ficam submetidos ao mesmo imperativo: publique para assegurar sua existência acadêmica! A responsabilização individual pela baixa produtividade observada em parcela significativa dos pesquisadores é percebida isoladamente dos fatores que delimitam a produtividade como um valor e a produzem como fenômeno de distorção da relação com o conhecimento; o resultado é a degradação do conceito de produção intelectual e a infusão de culpa a todos aqueles que não se ajustam à operacionalização desse efeito do trabalho intelectual em função da produção serial de tecnologias mensuráveis de acordo com a racionalidade da produção industrial.

Tem se tornado frequente a exigência de que alunos de pós-graduação, de cursos de mestrado e de doutorado dependentes do cômputo de suas produções para assegurar o reconhecimento da excelência da formação que promovem, obrigatoriamente publiquem artigos durante seu processo de formação como pesquisadores para que, efetivamente, possam levar a cabo a conclusão de seus cursos. Se não houver sequer a submissão de manuscritos relacionados às respectivas pesquisas, candidatos aos títulos de mestre e doutor talvez não possam sequer defender aquele que tradicionalmente foi reconhecido como o produto principal dessa etapa da formação: a tese de doutorado ou a dissertação de mestrado. Esse tipo de exigência, somada a tantas outras que definem essa etapa da formação, tem promovido e intensificado o sofrimento dos pesquisadores ingressantes, que veem suas aspirações de produzir obras de relevância científica serem frustradas pela necessidade pragmática de ajustamento à produção serial. Não raro, o desespero decorrente dessa condição é propagado e ressoa no empenho de alunos e orientadores para assegurar, mesmo que ao custo do adoecimento físico e psíquico, que suas produções possam ser avaliadas e, quiçá, aprovadas pelos periódicos científicos bem posicionados nos rankings nacionais e internacionais.

Com os pesquisadores profissionais, sobretudo docentes das universidades e institutos de pesquisa públicos, a situação não é diferente, pois sua manutenção em Programas de Pós-Graduação e a possibilidade de obterem recursos para pesquisa - aquisição de insumos de pesquisa, bolsas para seus orientandos, passagens para cooperações internacionais, verba para publicações etc. - dependem diametralmente de sua capacidade de publicação, em especial de artigos em periódicos bem avaliados, preferencialmente em língua inglesa.

Para além do que pode ser classificado por meio de diagnósticos psiquiátricos - síndrome de burnout, ansiedade, depressão, estresse etc. -, o sofrimento produzido por essas condições de trabalho tem conotação moral, caracterizada pela degradação da autoimagem e pela subsequente desabilitação das disposições essenciais para o trabalho de formadores. Quer o ajustamento cego às exigências de produtividade, quer a impossibilidade de atendê-las, implicam na obstrução da atividade intelectual mais importante para quem se dedica à formação de profissionais e de pesquisadores: a capacidade de refletir sobre o próprio trabalho sem sacrificar o amor pelo conhecimento e pela possiblidade de ensiná-lo.

A esse respeito, em uma palestra proferida na Casa do Estudante de Frankfurt, em 1962, Adorno (1963/2000) ponderou que, com relação a sua experiência como avaliador da prova geral de filosofia no concurso para docência em ciências nas escolas superiores do estado de Hessen, na Alemanha, interessava-lhe mais a autoconsciência do espírito, que permite ultrapassar o empreendimento particular de determinas áreas das ciências parcelares, do que as insígnias de valor presentes no modo pelo qual a pessoa se formou. Para ele, que fez muito duras críticas à pseudoformação, o que mais importava era a disposição para a autorreflexão, a qual pressupõe a formação, mas não determina de maneira definitiva o percurso de sua aquisição. A ausência da formação em pretensos formadores fora notada por ele como ponto central para sua avaliação, e esta parece manter estreita relação com o problema delimitado nessa análise da relação entre o imperativo da produção intelectual e a produção do sofrimento, disseminado entre pós-graduandos e orientadores, ambos supostamente devotados à condição de formadores. Disse Adorno:

A colcha de retalhos formada de declamação ideológica e de fatos que foram apropriados, isto é, na maior parte das vezes decorados, revela que foi rompido o nexo entre objeto e reflexão. A constatação disso nos exames é recorrente, levando imediatamente a concluir pela ausência da formação (Bildung) necessária a quem pretende ser um formador. (Adorno, 1963/2000, p. 63) 
No afã de fomentar a formação cultural por meio da qualificação das instituições acadêmicas, Adorno apontou para a necessidade de estimular a seleção de pessoas de espírito e não de pessoas altamente produtivas, como tanto se almeja. Incomodou-o a predominância de uma consciência coisificada que busca se apoiar em caminhos já consolidados, que lhes asseguram proteção quanto ao desafio do conhecimento. A ele preocupava se as pessoas que se encarregariam de formar as novas gerações e teriam uma "pesada responsabilidade quanto ao desenvolvimento real e intelectual da Alemanha, enquanto professores de escolas superiores" (p. 54) eram, de fato, intelectuais ou meros profissionais.

Como se pode notar, a preocupação de Adorno é digna de um avaliador comprometido com os fins da formação e do conhecimento que produzimos e não negligencia, de modo algum, a necessidade de se avaliar criteriosamente tais esferas. Para os propósitos de nossa reflexão, vale destacar a atualidade de suas ponderações e refletir sobre o quanto se aplicam também ao atual momento da academia brasileira.

O risco de institucionalizar formas determinadas de desonestidade intelectual mediante um sistema de avaliação que supervaloriza o volume de produção e seu impacto artificial, medido por meio de citações nem sempre espontâneas, parece ser incompatível com a exigência de formação cultural destacada por Adorno (1963/2000). Não obstante, o caráter falacioso do empreendimento que mobiliza a todos em função de critérios arbitrariamente constituídos, a pressão decorrente da necessidade de alimentar a máquina se tonou premente. Pode-se dizer que, com raras exceções, medeia o cotidiano dos trabalhadores acadêmicos e estudantes de modo pouco saudável. Em geral, as tarefas acadêmicas requerem dedicação plena; invadem o cotidiano daqueles que se dedicam a essa inglória condição, sufocando-os. Com isso, as fronteiras entre a vida pessoal e a atividade profissional passam a ser relativizadas e a necessidade de mais tempo para o trabalho parece confirmar a asseveração pessimista de Schopenhauer (1851/1999) a respeito da premência do tempo: "Também contribui para o tormento de nossa existência, e não pouco, o impelir do tempo, impedindonos de tomar fôlego, perseguindo todos qual algoz de açoite. Somente não o faz com aquele que se entregou ao tédio" (p. 278). Schopenhauer, por certo, não tinha em mente algo semelhante à atual pressão produtivista, que é típica do trabalho de pesquisadores contemporâneos, inclusive brasileiros, mas sim a tensão inerente à existência que não sucumbiu ao tédio, concedendolhe um status de pessimismo metafísico, de modo que, segundo sua concepção, "as pessoas sofrem pelo apetite insatisfeito de sua cega vontade, ou se entendiam tão pronto aquele esteja satisfeito" (Adorno, 1969/1995, p. 75). Todavia, sua asseveração desvela o potencial opressivo da operacionalização do tempo em função de tarefas que, para serem cumpridas na proporção requerida pelos sistemas avaliativos pouco afeitos ao conceito de formação (Bildung), requerem precisamente o tédio; que, independentemente da ambiguidade presente na teoria schopenhaeuriana do sofrimento, se apresenta para nós como uma condição contraditória: por um lado, necessária para que se possa responder às exigências que, mediante a percepção do impelir do tempo, teríamos intensa dificuldade em atender; de outro, intensifica o nível de desprazer contido na condição que se forma a partir da dissolução heteronômica da fronteira que delimitava o tempo de trabalho e o tempo livre, de modo a estimular a necessidade compulsiva de demarcar nitidamente os âmbitos da atividade profissional e da vida pessoal.

Em sua análise da apropriação do tempo livre pela racionalidade inerente à sociedade produtiva, Adorno $(1969 / 1995)$ se deteve sobre o estado de letargia ao qual grande parte das pessoas sucumbiu. Com isso, pôde tecer considerações críticas sobre o tédio e sua relação com as disposições psíquicas que deterioram as forças de resistência daqueles que são capturados em sua órbita:

Tédio é o reflexo do cinza objetivo. Ocorre com ele algo semelhante ao que se dá com a apatia política. A razão mais importante para esta última é o sentimento, de nenhum modo injustificado das massas, de que com a margem de participação na política que lhes é reservada pela sociedade, pouco podem mudar em sua existência, bem como, talvez em todos os sistemas da terra atualmente. O nexo entre a política e os seus próprios interesses lhes é opaco, por isso recuam diante da atividade política. Em íntima relação com o tédio está o sentimento, justificado ou neurótico, de impotência: tédio é desespero objetivo. Mas, ao mesmo tempo, também a expressão de deformações que a constituição global da sociedade produz nas pessoas. (p. 76)

Conforme o entendimento de Adorno (1969/1995), o tédio existe em função da vida que permanece indefinidamente sob a coação cotidiana decorrente da rigorosa divisão do trabalho. Para ele, o tédio:

Não teria que existir. Sempre que a conduta no tempo livre é verdadeiramente autônoma, determinada pelas próprias pessoas enquanto seres livres, é difícil que se instale o tédio. . . Se as pessoas pudessem decidir sobre si mesmas e sobre suas vidas, se não estivessem encerradas no sempre-igual, então não se entediariam. (p. 76)

Essa intrusão do funcionamento administrativo nos diversos âmbitos da vida, inclusive na atividade científica, de modo a imprimir os seus ritos e ritmo específicos, gera um paradoxo que requer reflexão: as atividades que poderiam produzir uma intervenção na realidade social, por meio da qual as pessoas poderiam se reconhecer como sujeitos, têm, elas mesmas, enquanto atividades que produzem impacto imediato na organização 
e significação da vida, se distanciado sobremaneira da qualidade de promotoras de reflexão, assemelhando-se ao que, sob a insígnia do hobby, Adorno (1969/1995) denominou pseudoatividade. Se o tempo não ocupado pelo trabalho, que poderia ser livre, não o é precisamente porque é organizado conforme a racionalidade que organiza a produção, e está presente na administração do ócio e na forma reproduzida pelos inúmeros produtos da indústria cultural que preenchem grande parte das atividades realizadas nessas circunstâncias, também as qualidades do pensamento, que se sustentam na liberdade de espírito, como a criatividade e a fantasia, elementos centrais à expressão artística e à experiência estética, são impedidas de se desenvolverem. Há muito que tais características estão banidas do trabalho alienado, organizado segundo o princípio da divisão de tarefas e da espoliação, com a crescente organização industrial da produção científica, também o trabalho intelectual por excelência, a pesquisa, se converte cada vez mais em trabalho alienado, sacrificando, igualmente, a criatividade e a fantasia. Seus efeitos nas atividades acadêmicas têm se alastrado incomensuravelmente à custa do extermínio da criatividade e da tão almejada inovação.

Também no âmbito do conhecimento conceitual, essas qualidades do pensamento são essenciais. Sem criatividade e sem fantasia, a ciência se torna mera constatação de fatos, uma forma de culto débil à realidade pálida. Semelhante ao desamparo imposto a todos em seu tempo livre, desprovido da fantasia, o trabalho intelectual é empurrado para o ferrenho positivismo que nega o sujeito em nome de uma objetividade artificialmente obtida por meio da primazia do método. A forma da produção intelectual se converte em extensão do método; com isso, o intento investigativo realiza um ritual de desencantamento que sacrifica o próprio pensamento, eliminando a vontade que nele se realiza. Paradoxalmente, o sofrimento dos pesquisadores que resistem a se adaptarem à produção serial - sua angústia diante da necessidade heteronomamente imposta de que convertam seu anseio pelo saber em volume de publicação-é sinal de que ainda há vida, de que ainda há vontade sob tensão. O pleno ajustamento, que negligencia e naturaliza o sofrimento, pelo contrário, revela a instalação eficaz e irrefreável do tédio.

A necessidade de demarcação rígida das esferas do trabalho e o do lazer há muito já denota uma denúncia da degradação da capacidade criativa dos seres humanos sob as condições de trabalho alienado. Quando essa mesma necessidade se afirma de modo tão veemente também em relação ao trabalho acadêmico, tornar-se mister considerar o nível de regressão a que este sucumbiu, recaindo igualmente nas condições de trabalho alienado. Torna-se imprescindível observar que a redação e publicação em larga escala de papers científicos atende a interesses alheios à necessidade de produção de conhecimento e que, assim estranhado de sua finalidade, o trabalho intelectual também se torna objeto de fetiche. A despeito de sua redução a valor de troca, que converte o conhecimento em mercadoria e os indicadores de produção em moeda, em capital, a produção fetichizada de papers confere à atividade científica o modus operandi da produção industrial. Com isso, também a racionalidade própria a essa forma produtiva é incorporada pela pesquisa acadêmica. A notória tendência à organização do trabalho de pesquisa e de divulgação, de modo a se obter maior eficácia produtiva, tem favorecido a aglomeração de pesquisadores em equipes coordenadas por pesquisadores seniores e colaboradores em diferentes níveis da formação e da carreira nas universidades e centros de pesquisa. Com isso, o trabalho em equipe, que pode muito bem resultar em cooperações de altíssima qualidade, tem se mostrado, também e principalmente, como a expressão contraditória da pesquisa administrada. A divisão do trabalho de pesquisa acelera o processo produtivo e assegura a eficácia pretendida, não obstante, intensifica os níveis de alienação em relação ao trabalho desenvolvido e, consequentemente, a necessidade de demarcação precisa da atividade profissional e da atividade intelectual não vinculada formalmente às tarefas profissionais. Em uma breve ponderação sobre o trabalho em equipe para investigação social, Adorno (1957/2001) destacou que a organização do trabalho de pesquisa por meio da divisão de tarefas pode resultar no empobrecimento dos momentos de reflexão, contrariando o que poderia, precisamente, assegurar a superação da arbitrariedade de cada um dos pesquisadores envolvidos. Como pôde indicar:

De este modo no solo es posible llevar a cabo un número de tareas mucho mayor del que podría resolver individualmente cada uno de los colaboradores si se enfrentara al conjunto del material sin la ayuda de los demás, sino que todos los trabajos que pasan por la maquinaria acaban por volverse tan compatibles, por asemejarse tanto entre sí, que la falta de integración teórica de los resultados del conjunto de la social research se hace doblemente paradójica: el precio que ha de pagarse por ese streamlining de las ciencias sociales es muy elevado. (Adorno, 1957-2001, pp. 60-61)

Para os propósitos desta reflexão, a crítica formulada por Adorno a respeito da pesquisa administrada nos auxilia a perceber com maior nitidez os fatores que impulsionam também os cientistas a buscarem subterfúgio no lazer para compensar as agruras do trabalho alienado. Essa constatação é importante, pois somente com muito esforço é possível demarcar com precisão a diferença efetiva entre ler obras literárias que nos promovam experiência estética apenas pela qualidade da experiência que promovem independentemente de sua importância para a investigação científica, ou entrar em contato com essas obras porque constituem um corpo de conhecimento não menos importante do que o conhecimento conceitual validado pelo método científico. Quando a dificuldade espontânea de diferenciar experiências em função de suas 
respectivas aplicações no trabalho ou como expressões do lazer se mostra como um problema a ser superado, pode-se ponderar que a cisão entre trabalho e tempo livre já se impõe integralmente também ao trabalho acadêmico e que a racionalidade tecnológica (Marcuse, 1964/2015) já medeia também a atividade intelectual.

A consciência acerca dessa cisão é fundamental para que se possa compreender por que o trabalho acadêmico tem se convertido em intensa fonte de sofrimento. Não se trata do sofrimento decorrente do confronto com o objeto do conhecimento, o qual, em razão de sua primazia, requer reflexão e autocrítica ao sujeito, mas sim do sofrimento artificialmente insuflado nos pesquisadores por um tipo de organização do trabalho acadêmico que atende cegamente ao imperativo da produção.

Entre a tormenta desencadeada pelo impelir administrado do tempo e o tédio que permeia o tempo supostamente livre, além de mediar também a relação heteronômica com o conhecimento, sobressai, em ambas as esferas, a primazia da racionalidade tecnológica. A atividade intelectual está reduzida à pseudoatividade, desvinculada de sua relação efetiva com os objetos, desprovida do encanto que historicamente esteve presente na formação cultural sob a forma de amor ao objeto (Adorno, 1963/2000). Sem esse encanto, sobrevém o feitiço da mercadoria que se torna independente do seu processo de produção, sucumbindo ao fetichismo.
Sob o imperativo da produção acadêmica, os pesquisadores - pós-graduandos ou docentes - sofrem a pressão das agências de avaliação que exigem volumes crescentes de "produtos" que atestem sua capacidade produtiva, mas sofrem também do tédio desencadeado pela apropriação maquinal da criatividade. Para além do sofrimento desencadeado pela vontade de conhecer em circunstâncias nas quais se é compelido a produzir em um tempo incompatível com o ato mesmo da investigação, o tédio se revela como o efeito mais daninho do produtivismo, pois se apoia no sacrifício do desejo de conhecer.

Se não é possível haver neutralidade na relação entre conhecimento e política, a apatia que se instaura na esfera política, na atitude que diante dela regride a uma postura impotente, é precisamente na política acadêmica que a relação entre esses dois elementos mais se intensifica: como expressão de desespero objetivo (Adorno, 1969/1995), o tédio é continuidade do sofrimento diante da exigência de adaptação, de sacrifício da criatividade e da liberdade de espírito, mas também é efeito da deformidade imposta por esse sistema que impõe sua determinação a todos que ousam pensar.

Se o sofrimento decorrente da consciência da opressão não nos calar, sua força poderá se tornar libertadora, permitindo reafirmar o valor daquilo mesmo que fazemos com amor: a formação, a pesquisa e a crítica.

\section{Referências}

Adorno, T. W. (1995). Tempo livre. In T. W. Adorno, Palavras e sinais: modelos críticos (M. H. Ruschel, trad., pp. 70-82). Petrópolis, RJ: Vozes. (Trabalho original publicado em 1969)

Adorno, T. W. (2000). A filosofia e os professores. In T. W. Adorno, Educação e emancipação (W. L. Maar, trad., 2a ed., pp. 51-74). São Paulo, SP: Paz e Terra. (Trabalho original publicado em 1963)

Adorno, T. W. (2001). Trabajo en equipo e investigación social. In T. W. Adorno, Espistemología y ciencias sociales (V. Gómes, trad., pp. 59-63). Madrid, España: Frónesis/Cátedra Universitat de València. (Trabalho original publicado em 1957)

Adorno, T. W. (2004). Capitalismo tardío o sociedad industrial? In T. W. Adorno, Escritos sociológicos I-obra completa, 8 (A. G. Ruiz, trad., pp. 330-344). Madrid, España: Akal. (Trabalho original publicado em 1968)
Marcuse, H. (2015). O homem unidimensional: estudos da ideologia da sociedade industrial avançada (R. Oliveira, D. C. Antunes, \& R. C. Silva, trads.). São Paulo, SP: Edipro. (Trabalho original publicado em 1964)

Oliveira, M. B. (2015). A epidemia das más condutas na ciência: o fracasso do tratamento moralizador. Scientiae Studia, 13(4), 867-897. Recuperado de https://goo. $\mathrm{gl} / 8 \mathrm{veEHQ}$

Schmidt, M. L. (2011). Avaliação acadêmica, ideologia e poder. Psicologia USP, 22(2), 315-334. Recuperado de https://goo.gl/i1s9PU

Schopenhauer, A. (1999). Parerga e paralipomena: pequenos escritos filosóficos (capítulos V, VIIII, XII, XIV). In A. Schopenhauer, Os pensadores: Schopenhauer (W. L. Maar, trad., pp. 237-300). São Paulo, SP: Abril Cultural. (Trabalho original publicado em 1951) 